\title{
SIMULATION OF HYDROTREATING OF VEGETABLE OIL IN A SLURRY BUBBLE COLUMN REACTOR FOR GREEN DIESEL PRODUCTION
}

\author{
Yuswan Muharam ${ }^{1 *}$, Adinda Diandri Putri ${ }^{1}$ \\ ${ }^{1}$ Department of Chemical Engineering, Faculty of Engineering, Universitas Indonesia, \\ Kampus UI Depok, Depok 16424, Indonesia
}

(Received: March 2018 / Revised: June 2018 / Accepted: September 2018)

\begin{abstract}
The purpose of this research is to obtain a mathematical model of the hydrotreating of vegetable oil in a slurry bubble column reactor to produce green diesel using an NiMo- $\mathrm{P} / \mathrm{Al}_{2} \mathrm{O}_{3}$ catalyst. A steady state two-dimensional axisymmetric model of a slurry bubble column reactor of $2.68 \mathrm{~m}$ in diameter and $7.14 \mathrm{~m}$ in height was developed. The numerical simulation was performed using the model for the reactor operating at 34.5 bar and $598 \mathrm{~K}$. Triglyceride of $5 \mathrm{wt} \%$ in dodecane enters the reactor with a very low velocity so that it resembles a batch operation. Hydrogen of $188 \mathrm{~mol}$ hydrogen/triglyceride enters the reactor with a velocity of $0.02 \mathrm{~m} / \mathrm{s}$. The simulation results show that the vegetable oil (triglyceride) conversion is $97.73 \%$, the product yield is 83.34 $\mathrm{wt} \%$ and the product purity is $77.23 \mathrm{wt} \%$.
\end{abstract}

Keywords: Green diesel; Modeling; Simulation; Slurry bubble column; Vegetable oil

\section{INTRODUCTION}

The depletion of global fossil fuels accompanied by the increase in energy demand and the attention to environmental damage due to the combustion of said fuels have motivated researchers to focus on renewable energy production and utilization. Hydrogen, liquefied petroleum gases, liquefied natural gas, biomass, biodiesel, and green diesel are some alternative energy sources that are being researched and considered as possible fossil fuel replacements (Elvan et al., 2013). Green diesel is one of the most promising alternative fuels and is expected to replace petroleum diesel fuel in the future due to its superior properties.

Green diesel is a second generation biofuel and is mainly produced from vegetable oils. It consists of straight-chain alkanes with 15-18 carbon atoms, the chemical structures of which are identical to those of petroleum diesel. The significant difference between green diesel and biodiesel is in their molecular structures. While biodiesel comprises alkyl ester molecules, green diesel consists of paraffin molecules, i.e., green diesel does not contain oxygen-based molecules. This characteristic of green diesel results in high heating value and high energy density (U.S. Department of Energy, 2007). Other properties of green diesel superior to biodiesel are a higher quality cetane component $(\mathrm{CN}>80)$, lower $\mathrm{NO}_{\mathrm{x}}$ emissions, better oxidative stability, higher fulfilment of car manufacturer requirements, and higher applicability in all diesel vehicles (Kalnes et al., 2007).

Hydroprocessing or hydrotreating reaction is one of the alternative methods to produce green diesel. It is considered the most favorable method and has been applied in industries. Its

\footnotetext{
${ }^{*}$ Corresponding author's email: muharam@che.ui.ac.id, Tel. +62-21-7863576, Fax. +62-21-7863515 Permalink/DOI: https://doi.org/10.14716/ijtech.v9i6.2362
} 
mechanism includes hydrogenation, decarbonylation, decarboxylation, and hydrodeoxygenation. Hydrodeoxygenation eliminates oxygen by reacting triglycerides and free fatty acids with hydrogen to form water and n-paraffins. Decarboxylation or decarbonylation eliminates oxygen to form carbon dioxide or carbon monoxide and n-paraffins. The process involves three phases: vegetable oil (triglycerides) as the liquid phase, hydrogen as the gas phase, and a catalyst as the solid phase.

The most frequently used three-phase reactors are trickle-bed reactors and slurry reactors. A trickle-bed reactor is a type of fixed-bed reactor. A slurry reactor is a type of bubble column or stirred reactor. In slurry bubble column reactors, agitation by gas bubbles causes catalyst particles to be suspended in liquid. Slurry bubble column reactors have many advantages compared to trickle-bed reactors, such as better temperature control and heat removal, lower pressure drop (four times less than in fixed-bed reactors), the ability to use finer catalyst particles $(<100 \mu \mathrm{m})$ allowing for a large surface area and better mass transfer, higher yield per reactor volume, and ease of continuous addition and removal of catalyst particles (Sehabiague et al., 2008).

Experimental and kinetics studies of hydrotreating have been conducted for various feedstocks by many researchers: Sotelo-Boyas et al. (2011) used rapeseed oil with supported nickel catalysts, Kumar et al. (2014) employed stearic acid with supported nickel catalysts; Zhang et al. (2014) utilized waste cooking oil with a dispersed nanocatalyst, Manco (2014) used palm oil with supported nickel catalysts, and Landberg (2017) employed tall oil with supported nickel catalysts.

Modeling and simulation help experimental work on a particular process as they save time and cost. With modeling and simulation, one learns process behavior from which an optimal process can be designed. Although the advantages of modeling are remarkable, research on modeling of hydrotreating reactors is scarce. Research on the modeling of hydrotreating reactors has been performed by Attanatho (2012) using a microchannel reactor and Muharam et al. (2017a, 2017b) using a trickle-bed reactor.

The present study aims to obtain a mathematical model of the hydrotreating of vegetable oil to produce green diesel in a slurry bubble column reactor using an NiMo-P/Al $\mathrm{O}_{3}$ catalyst and to understand the hydrotreatment behavior in the reactor.

\section{METHODS}

Figure 1 illustrates the slurry bubble column reactor, which is modeled in this study. The steady state two-dimensional axisymmetric model of a slurry bubble column reactor with the diameter of $2.68 \mathrm{~m}$ and the length of $7.14 \mathrm{~m}$ was developed by considering mass transfer in gas and liquid phase and heat transfer. The reactor operates under the operating condition of 34.5 bar in pressure and $598 \mathrm{~K}$ in temperature. The kinetic model developed by Attanatho (2012) was adopted. In the model, hydrogen and triglyceride are the reactants, and heptadecane $\left(\mathrm{C}_{17}\right)$ and octadecane $\left(\mathrm{C}_{18}\right)$ are the main products.

Triglycerides (or triolein) and gaseous hydrogen enter the reactor through the bottom. The gas bubbles traveling upwards along the reactor agitate the solid phase (catalyst) suspended in liquid, leading to the mixing of the three phases. Unconverted hydrogen and volatile products exit the reactor from the top. Unconverted triglycerides and liquid products are withdrawn from the reactor side.

\subsection{Mass Transfer}

The governing equation for the gas-phase mass transfer in the reactor is described by:

$$
D_{\mathrm{G}} \varepsilon_{\mathrm{G}}\left(\frac{1}{r} \frac{\partial}{\partial r}\left(r \frac{\partial C_{\mathrm{G}, i}}{\partial r}\right)+\frac{\partial^{2} C_{\mathrm{G}, i}}{\partial z^{2}}\right)-\left(u_{\mathrm{G}, z} \frac{\partial C_{\mathrm{G}, i}}{\partial z}\right)-R_{\mathrm{GL}, i}=0
$$




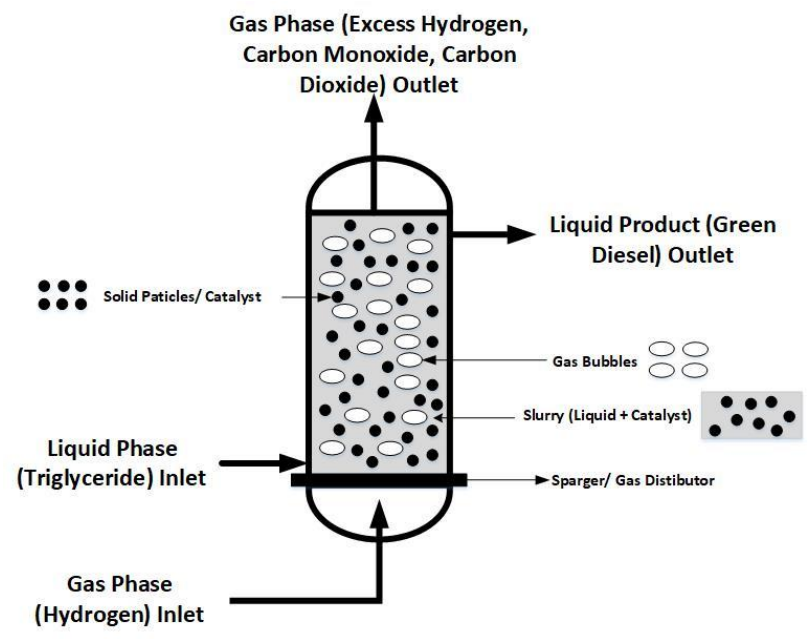

Figure 1 Slurry bubble column reactor

where $C_{\mathrm{G}, i}$ is the gas-phase concentration of component $i, u_{\mathrm{G}, Z}$ is the axial gas superficial velocity, $\varepsilon_{\mathrm{G}}$ is the gas holdup and $R_{\mathrm{GL}, i}$ is the gas-liquid mass transfer rate of component $i$. The gas-phase mixing is expressed by dispersion coefficient $D_{\mathrm{G}}$.

The mass transfer in the liquid phase is described by Equation 2 as follows:

$$
D_{\mathrm{L}} \varepsilon_{\mathrm{L}}\left(\frac{1}{r} \frac{\partial}{\partial r}\left(r \frac{\partial C_{\mathrm{L}, i}}{\partial r}\right)+\frac{\partial^{2} C_{\mathrm{L}, i}}{\partial z^{2}}\right)-\left(u_{\mathrm{L}, \mathrm{z}} \frac{\partial C_{\mathrm{L}, i}}{\partial z}\right)+R_{\mathrm{GL}, i}-R_{i}=0
$$

where $C_{\mathrm{L}, \mathrm{i}}$ is the liquid-phase concentration of component $i, u_{\mathrm{L}, \mathrm{z}}$ is the axial liquid superficial velocity, $\varepsilon_{\mathrm{L}}$ is the gas holdup, $R_{i}$ is the chemical reaction rate of component $i$ and $D_{\mathrm{L}}$ is the liquidphase dispersion coefficient.

\subsection{Heat Transfer}

Thermal equilibrium is assumed to happen such that the temperature difference between the phases can be neglected. The governing equation for heat transfer is as follows:

$$
\left(\rho C_{p}\right)\left(u_{\mathrm{z}} \frac{\partial T}{\partial z}\right)-\frac{\partial}{\partial z}\left(k_{\mathrm{eff}} \frac{\partial T}{\partial z}\right)=Q
$$

where $T$ is temperature, $u_{\mathrm{z}}$ is the fluid axial superficial velocity, $\rho$ is the slurry density, $C_{p}$ is the slurry heat capacity, $k_{\text {eff }}$ is the effective thermal conductivity and $Q$ is the heat reaction.

\subsection{Chemical Kinetics}

The kinetics used in this study are from the kinetic model developed by Attanatho (2012) based on the reaction mechanism, as exhibited in Figure 2. The reaction mechanism involves 13 species: triglycerides (TG); diglycerides (DG), monoglycerides (MG), free fatty acids (FFA), alcohol or fatty alcohol (FA), long chain esters (ET), $\mathrm{C}_{17} \mathrm{H}_{36}$ hydrocarbons $\left(\mathrm{C}_{17} \mathrm{HC}\right), \mathrm{C}_{18} \mathrm{H}_{38}$ hydrocarbons $\left(\mathrm{C}_{18} \mathrm{HC}\right), \mathrm{CO}, \mathrm{CO}_{2}, \mathrm{H}_{2}, \mathrm{H}_{2} \mathrm{O}$, and propane $\left(\mathrm{C}_{3} \mathrm{HC}\right)$. Table 1 shows the reaction rate expressions for each reaction step. 


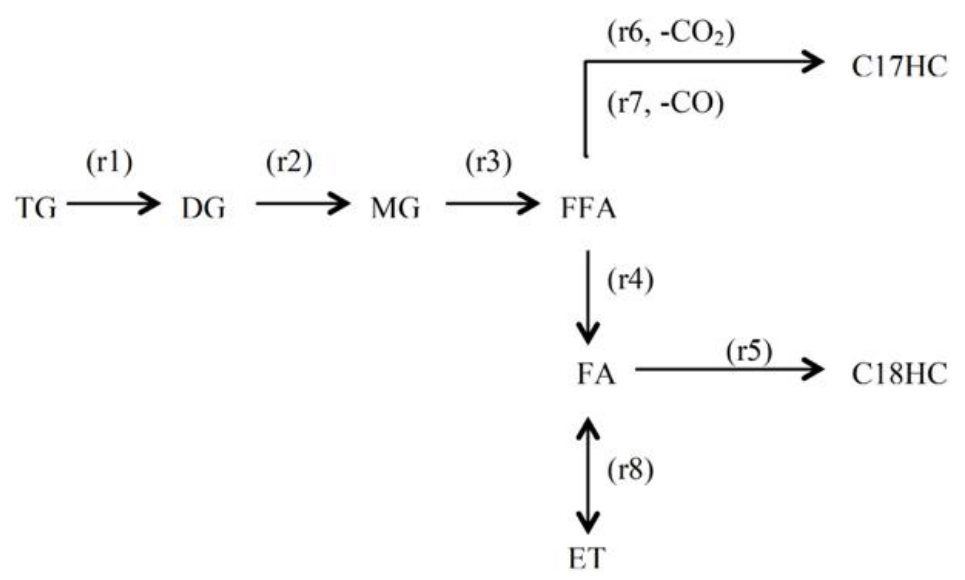

Figure 2 Mechanism of triglyceride hydroprocessing reaction

Table 1 Reactions and reaction rate equation expressions in the hydrotreating of triglyceride (Attanatho, 2012)

\begin{tabular}{cll}
\hline No. & \multicolumn{1}{c}{ Stoichiometry } & \multicolumn{1}{c}{ Reaction Rate } \\
\hline$r_{1}$ & $\mathrm{TG}+\mathrm{H}_{2} \rightarrow \mathrm{FFA}+\mathrm{DG}$ & $r_{1}=k_{1} \mathrm{C}_{\mathrm{TG}}$ \\
$r_{2}$ & $\mathrm{DG}+\mathrm{H}_{2} \rightarrow \mathrm{FFA}+\mathrm{MG}$ & $r_{2}=k_{2} \mathrm{C}_{\mathrm{DG}}$ \\
$r_{3}$ & $\mathrm{MG}+\mathrm{H}_{2} \rightarrow \mathrm{FFA}+\mathrm{C} 3 \mathrm{HC}$ & $r_{3}=k_{3} \mathrm{C}_{\mathrm{MG}}$ \\
$r_{4}$ & $\mathrm{FFA}+2 \mathrm{H}_{2} \rightarrow \mathrm{FA}+\mathrm{H}_{2} \mathrm{O}$ & $r_{4}=k_{4} \mathrm{C}_{\mathrm{FFA}}$ \\
$r_{5}$ & $\mathrm{FA}+\mathrm{H}_{2} \rightarrow \mathrm{C} 18 \mathrm{HC}+\mathrm{H}_{2} \mathrm{O}$ & $r_{5}=k_{5} \mathrm{C}_{\mathrm{FA}}$ \\
$r_{6}$ & $\mathrm{FFA} \rightarrow \mathrm{C} 17 \mathrm{HC}+\mathrm{CO}_{2}$ & $r_{6}=k_{6} \mathrm{C}_{\mathrm{FFA}}$ \\
$r_{7}$ & $\mathrm{FFA}+\mathrm{H}_{2} \rightarrow \mathrm{C} 17 \mathrm{HC}+\mathrm{CO}+\mathrm{H}_{2} \mathrm{O}$ & $r_{7}=k_{7} \mathrm{C}_{\mathrm{FFA}}$ \\
$r_{8}$ & $\mathrm{FA}+\mathrm{FFA} \leftrightarrow \mathrm{ET}+\mathrm{H}_{2} \mathrm{O}$ & $r_{8}=k_{8} \mathrm{C}_{\mathrm{FFA}} \mathrm{C}_{\mathrm{FA}}-k_{9} \mathrm{C}_{\mathrm{ET}} \mathrm{C}_{\mathrm{H} 2 \mathrm{O}}$ \\
\hline
\end{tabular}

\subsection{Pressure Drop}

The pressure drop due to the friction is much smaller relative to that of the static height. The governing equation to calculate the pressure drop along the reactor is proposed by Schweitzer and Viguié (2009):

$$
\frac{\partial P}{\partial z}=-\left(1-\varepsilon_{\mathrm{G}}\right) g \rho
$$

\subsection{Catalyst Distribution}

The catalyst distribution along the reactor is proposed by Deckwer and Serpemen (1982):

$$
w(\xi)=\bar{w} B o_{\mathrm{c}} \exp \left(-B o_{\mathrm{c}} \xi\right)\left[1-\exp \left(-B o_{\mathrm{c}}\right)\right]^{-1}
$$

where $\bar{w}$ is the average catalyst distribution, $B o_{\mathrm{c}}$ is the catalyst Bodenstein number and $\xi$ is the ratio of the $z$ position to the reactor length.

\section{RESULTS AND DISCUSSION}

The process and geometric parameters are shown in Table 2. Triglyceride is the limiting reactant, and hydrogen is in excess. Triglyceride is diluted in dodecane with the concentration being 5 $\mathrm{wt} \%$. The triglyceride concentration is set at such a low level to prevent catalyst deactivation. 
Table 2 Process and geometric parameters for the simulation

\begin{tabular}{lr}
\hline \multicolumn{1}{c}{ Parameter } & \multicolumn{1}{c}{ Value } \\
\hline Reactor diameter & $2.68 \mathrm{~m}$ \\
Reactor length & $7.14 \mathrm{~m}$ \\
Catalyst particle diameter & $50 \mu \mathrm{m}$ \\
Inlet pressure & $500 \mathrm{psi}$ \\
Inlet temperature & $325^{\circ} \mathrm{C}$ \\
$\mathrm{H}_{2} /$ TG molar ratio in feed & 188 \\
Superficial gas velocity & $0.02 \mathrm{~m} / \mathrm{s}$ \\
Superficial liquid velocity & $0.00025 \mathrm{~m} / \mathrm{s}$ \\
TG concentration in liquid feed & $5 \mathrm{wt} \%$ \\
FFA/TG mass ratio in liquid phase & $5 \mathrm{wt} \%$ \\
Cooling fluid temperature & $325^{\circ} \mathrm{C}$ \\
\hline
\end{tabular}

\subsection{Concentration Profiles}

In the slurry bubble column, triglyceride (or triolein) molecules enter the reactor from the bottom. They then cross the liquid-solid film around the catalyst particles to reach the pore mouths. However, the model assumes that the mass transfer resistance between the liquid and solid phases is very small, so that the triglyceride concentration in the pore mouths is considered equal to that in the liquid phase. Figure 3a shows that the TG concentration in the liquid phase decreases in the axial direction. This demonstrates that triglycerides are consumed in the reactor.

The very small liquid superficial velocity in this study reflects that the liquid phase is in batchlike operation. The boundary for such an inlet condition is the Danckwerts boundary. The mass entering point $z=0$ of the reactor geometry is solely due to the convection flow. The mass leaving point $z=0$ is due to the convection flow and concentration gradient. The latter is induced by bubble agitation and chemical reactions. This gives rise to the triglyceride concentration in the liquid phase (around $0.08 \mathrm{~mol} / \mathrm{m}^{3}$ ) being much smaller than that entering the reactor $(3.69$ $\left.\mathrm{mol} / \mathrm{m}^{3}\right)$.

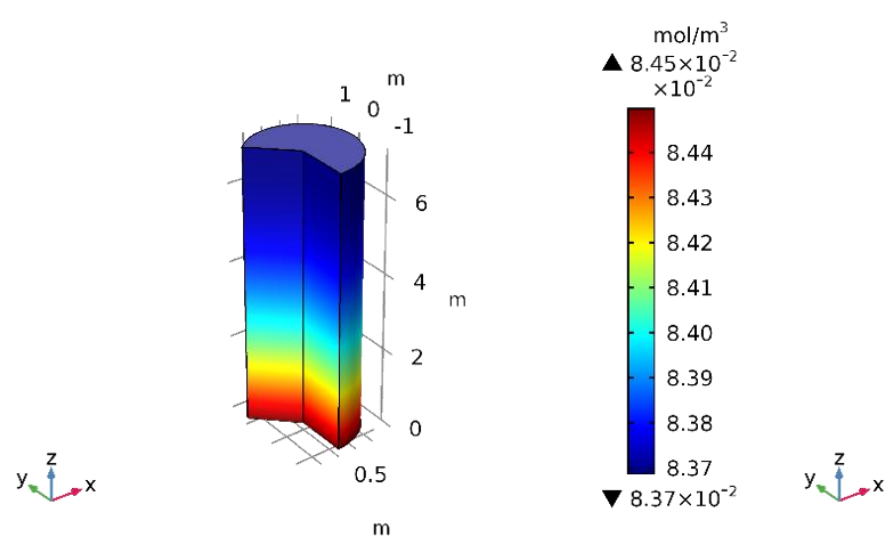

(a)

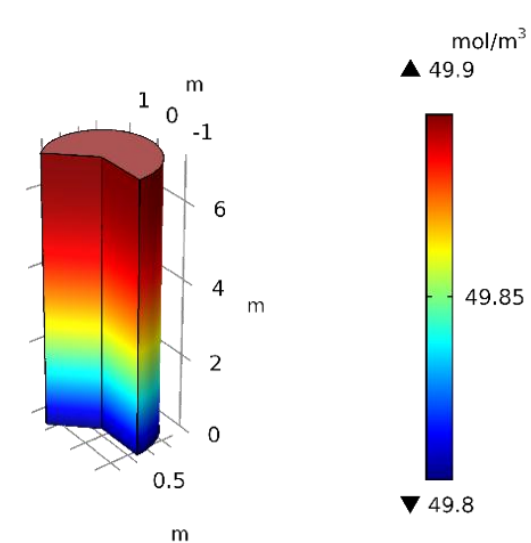

(b)

Figure 3 Concentrations in the liquid phase; (a) triglyceride and (b) hydrogen

Figure 3a shows that the mixing in the column is excellent. The triglyceride concentration in the radial direction is $0.0839 \mathrm{~mol} / \mathrm{m}^{3}$ at $z=3.57 \mathrm{~m}$. The triglyceride concentration in the axial direction ranges from $0.0845 \mathrm{~mol} / \mathrm{m}^{3}$ at $z=0 \mathrm{~m}$ to $0.0837 \mathrm{~mol} / \mathrm{m}^{3}$ at $z=7.14 \mathrm{~m}$. This indicates that the fluids are in a homogeneous bubble flow region. 
The kinetic model developed by Attanatho (2012) does not depend on the hydrogen concentration. This demands that the dissolved hydrogen concentration be excessive. Figure $3 \mathrm{~b}$ shows that the dissolved hydrogen concentration is around $49.85 \mathrm{~mol} / \mathrm{m}^{3}$, which is much higher than the triglyceride concentration (around $0.08 \mathrm{~mol} / \mathrm{m}^{3}$ ). This value for the dissolved hydrogen concentration is achieved when the hydrogen pressure is about $3.4 \times 10^{6} \mathrm{~Pa}$, given that the gasphase hydrogen concentration is approximately $693 \mathrm{~mol} / \mathrm{m}^{3}$ (Figure 4).

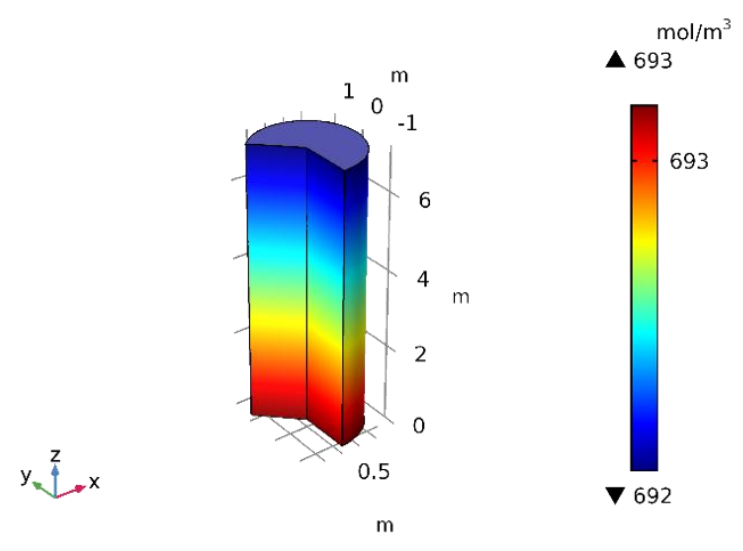

Figure 4 Hydrogen concentration in the gas phase

The saturated concentration of dissolved hydrogen calculated using Henry's constant at 34.5 bar is around $175.5 \mathrm{~mol} / \mathrm{m}^{3}$. There is a significant difference in the dissolved hydrogen concentration between its saturation and actual condition. It can be understood that the gas-liquid hydrogen mass transfer resistance is very high. The hydrogen mass transfer coefficient is $0.0004 \mathrm{~m} / \mathrm{s}$, and the specific surface area is $0.06 \mathrm{~m}^{2} / \mathrm{m}^{3}$.

Hydrotreating reactions produce green diesel consisting of heptadecane $\left(\mathrm{C}_{17}\right)$ and octadecane $\left(\mathrm{C}_{18}\right)$. Figures $5 \mathrm{a}$ and $5 \mathrm{~b}$ show that the $\mathrm{C}_{17}$ and $\mathrm{C}_{18}$ concentrations in the liquid phase increase along the axial direction. However, the concentration gradient is not significant, which indicates that the agitation by rising bubbles causes the mixture in the liquid phase to be homogeneous.

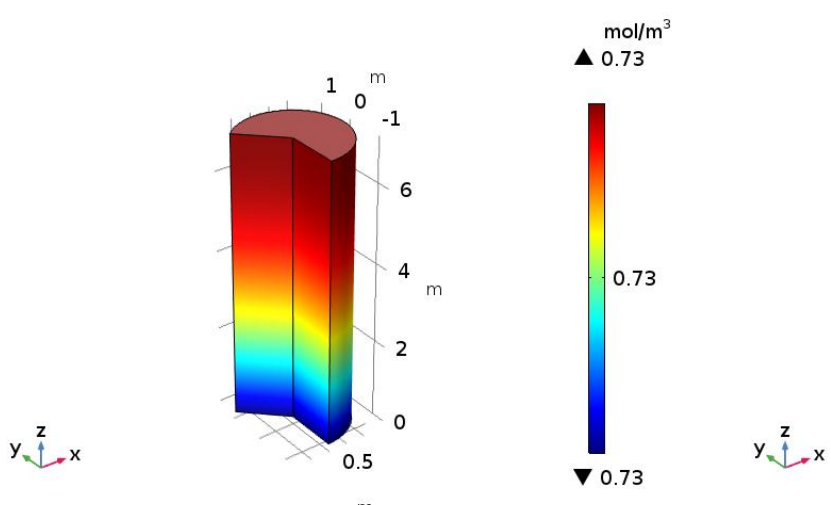

(a)

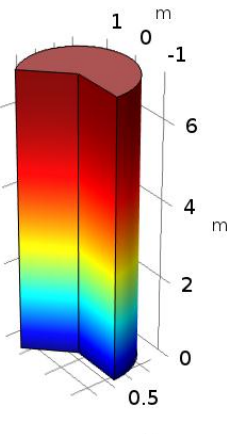

(b)

Figure 5 Concentrations in the liquid phase: (a) $\mathrm{C}_{17}$; and (b) $\mathrm{C}_{18}$

The $\mathrm{C}_{18}$ concentration is more than 10 times higher than the $\mathrm{C}_{17}$ concentration. $\mathrm{C}_{18}$ is produced through $r_{5}$ with FA as the reactant, while $\mathrm{C}_{17}$ is produced through $r_{6}$ and $r_{7}$ with FFA as the reactant. FFA produced through $r_{1}, r_{2}$ and $r_{3}$ is converted to FA. The rates of FFA production and consumption have the same order of magnitude. Considering the liquid superficial velocity is 
very small, the FA concentration in the reactor is much higher than the FFA concentration. Because the reactant for the $\mathrm{C}_{18}$ production is $\mathrm{FA}$ and for $\mathrm{C}_{17}$ is FAA, the rate of $\mathrm{C}_{18}$ production is higher than that of $\mathrm{C}_{17}$, even though $k_{7}$ is 10 times higher than $k_{5}$.

\subsection{Temperature Profile}

Figure 6 shows that the temperature in the reactor is practically homogeneous with only a very small difference between the reactor inlet and outlet (as indicated by the color change in Figure 6). This homogeneity is caused by good dispersion in the liquid phase and confirms the theory that, due to its good mixing property, a slurry bubble column reactor offers a relative ease of heat removal with less cooling area than some other types of hydroprocessing reactors (e.g., tricklebed).

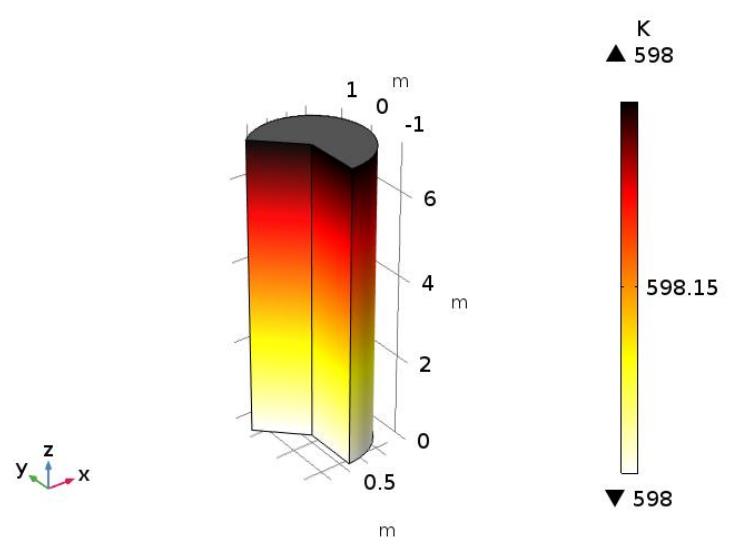

Figure 6 Temperature profile

This exothermic hydrotreating reactions generate heat up to $12300 \mathrm{~W} / \mathrm{m}^{3}$. With the cooling provided by the wall at which the temperature is the same as the gas feed temperature $(598.15$ $\mathrm{K})$, the cooling process takes place well. The fluid with the effective thermal conductivity of $0.0779 \mathrm{~W} / \mathrm{m} . \mathrm{K}$ is quite capable of transporting heat radially outward, and the thermal boundary layer formed on the wall surface demonstrates an excellent ability to remove heat from the reactor bed; thus, the temperature in the reactor is close to the gas feed temperature. This character is possessed by other three-phase reactors such as trickle-bed reactors only if the reactor's diameter is very small with a very high aspect ratio (Muharam et al., 2017a).

\subsection{Pressure Profile and Catalyst Distribution}

The changes in inertial and shear forces due to flowing gas in the reactor give rise to a pressure drop along the reactor. Figure 7 shows that the pressure in the reactor decreases from the inlet $(z$ $=0)$ to the outlet $(z=7.14 \mathrm{~m})$, i.e., the pressure drop develops in the reactor. The pressure drop is very small, 0.4 bar, due to the very small gas superficial rate. A fairly low-pressure drop is one of the advantages of a slurry bubble column reactor since it keeps operating costs low.

Figure 8 shows that the catalyst in the reactor is distributed along the reactor. It can be seen that the catalyst concentration decreases from the inlet $(z=0)$ to the outlet $(z=7.14 \mathrm{~m})$. It can be clearly observed that the higher catalyst concentration occurs near the bottom (inlet) of the reactor. This is due to the precipitation velocity of solid particles in a large swarm being higher than the liquid phase resistance (Nader, 2008). The very low difference in the catalyst concentration in axial direction has no significant effect on the triglyceride consumption rate since the temperature slightly increases in the axial direction. 


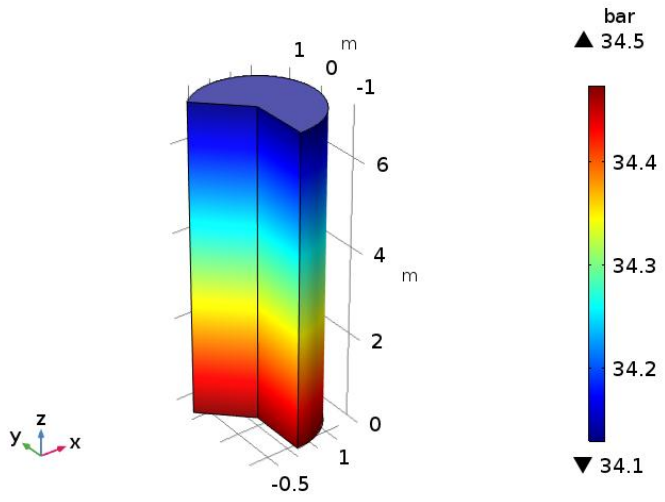

Figure 7 Pressure profile

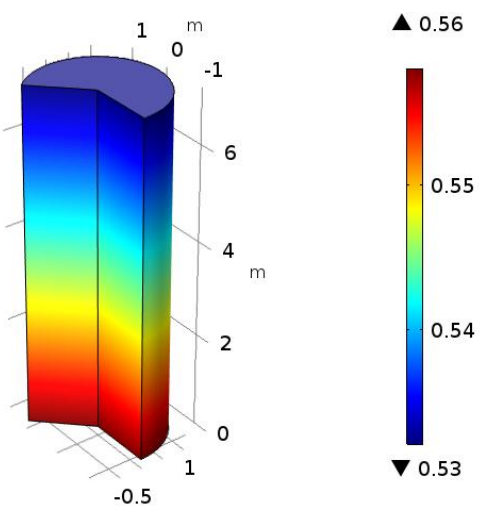

Figure 8 Catalyst distribution

\subsection{Reactor Performance}

The reactor performance is represented by the TG conversion, the green diesel yield and the green diesel purity. Figures 9 to 11 show the profiles of the reactor performances in the axial direction of the reactor. Uniform mass and temperature distribution in the reactor lead to the homogeneity of the triglyceride conversion, product selectivity and product yield. The triglyceride conversion reaches $97.73 \%$, indicating that the process in the reactor works well. The green diesel yield and selectivity are $83.32 \%$ and $77.22 \%$, respectively. Simulation results in a trickle-bed reactor of 10 $\mathrm{m}$ in length and 100 in aspect ratio with a hydrogen velocity of $0.03 \mathrm{~m} / \mathrm{s}$ gave a production rate of $28.42 \mathrm{~kg} /$ day with the triglyceride conversion being $78.58 \%$ and the green diesel purity being 96.75\% (Muharam et al., 2017a). This indicates that the process in a slurry bubble column reactor provides performance comparable with that of a multi-tubular trickle-bed reactor.

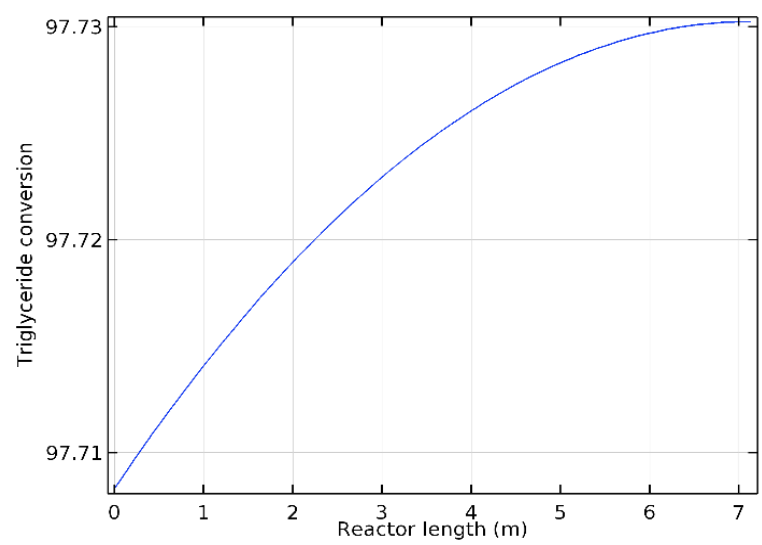

Figure 9 Triglyceride conversion

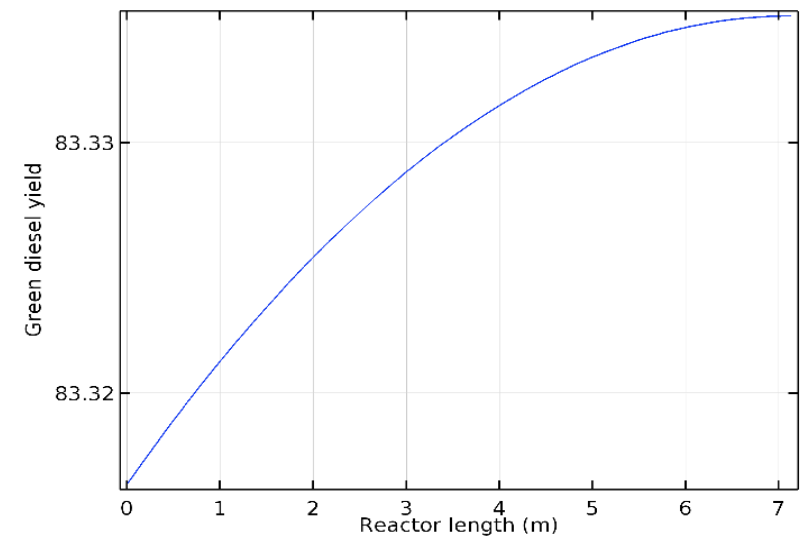

Figure 10 Green diesel $\left(\mathrm{C}_{17}\right.$ and $\left.\mathrm{C}_{18}\right)$ yield

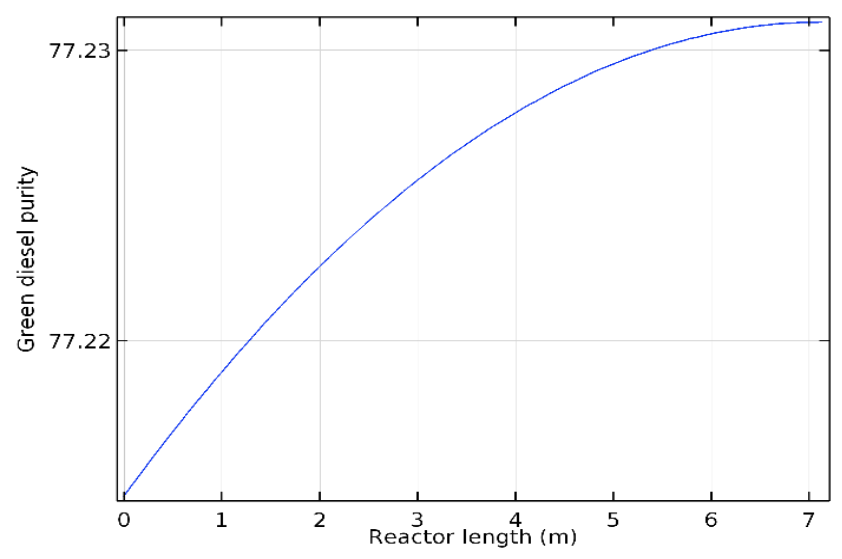

Figure 11 Green diesel $\left(\mathrm{C}_{17}\right.$ and $\left.\mathrm{C}_{18}\right)$ purity 


\section{CONCLUSION}

The simulation results using the model developed in this research show that the performance of the slurry bubble column reactor producing green diesel via hydrotreating of vegetable oil is excellent. The TG conversion, the green diesel yield, and the green diesel purity are $97.73 \%$, $83.34 \%$, and $77.23 \%$, respectively.

\section{ACKNOWLEDGEMENT}

We express our gratitude to the University of Indonesia, which funded this research through the Hibah Publikasi Internasional Terindeks untuk Tugas Akhir Mahasiswa (PITTA) scheme under the contract No 2573/UN.2.R3.1/HKP.05.00/2018.

\section{REFERENCES}

Attanatho, L., 2012. Performances and Kinetic Studies of Hydrotreating of Bio-oils in Microreactor. Dissertation, Doctoral, Oregon State University, United States

Deckwer, W.D., Serpemen, Y., 1982. Modeling the Fischer-Tropsch Synthesis in the Slurry Phase. Industrial \& Engineering Chemistry Process Design and Development, Volume 21(2), pp. 231-241

Elvan, S., Dimaggio, C., Kim, M., Salley, S.O., Simon, K.Y., 2013. Catalytic Conversion of Brown Grease to Green Diesel via Decarboxylation over Activated Carbon Supported Palladium Catalyst. Industrial \& Engineering Chemistry Research, Volume 52(33), pp. $11527-11536$

Kalnes, T., Marker, T., Shonnard, D.R., 2007. Green Diesel: A Second Generation Biofuel. International Journal of Chemical Reactor Engineering, Volume 5, pp. 1-11

Kumar, P., Yenumala, S.R., Maity, S.K, Shee, D., 2014. Kinetics of Hydrodeoxygenation of Stearic Acid using Supported Nickel Catalysts: Effects of Supports. Applied Catalysis A: General, Volume 471, pp. 28-38

Landberg, K., 2017. Experimental and Kinetic Modelling Study of Hydrodeoxygenation of Tall Oil to Renewable Fuel. Master's Thesis, Graduate Program, Chalmers University of Technology, Sweden

Manco, J.F.V., 2014. Conceptual Design of a Palm Oil Hydrotreatment Reactor for Commercial Diesel Production. Master's Thesis, Graduate Program, Universidad Nacional de Colombia, Medellín, Colombia

Muharam, Y., Nugraha, O.A., 2017a. Prediction of the Effects of the Inlet Velocity and the Reactor Length on the Performance of a Trickle-Bed Reactor for Renewable Diesel Production. Advanced Science Letters, Volume 23, pp. 5609-5614

Muharam, Y., Nugraha, O.A., Leonardi, D., 2017b. Modelling of a Hydrotreating Reactor to Produce Renewable Diesel from Non-edible Vegetable Oils. Chemical Engineering Transactions, Volume 56, pp. 1561-1566

Nader, A.A., 2008. Simulation of Gas-to-Liquid (GTL) Process in Slurry Bubble Column Reactor. Master's Thesis, Graduate Program, University of Technology, Iraq

Schweitzer, J.M., Viguié, J.C., 2009. Reactor Modeling of a Slurry Bubble Column for FischerTropsch Synthesis. Oil \& Gas Science and Technology, Volume 64(1), pp. 63-77

Sehabiague, L., Lemoine, R., Behkish, A., Heintz, Y.J., Sanoja, M., Oukaci, R., Morsi, B.I., 2008. Modeling and Optimization of a Large-scale Slurry Bubble Column Reactor for Producing 10,000 bbl/day of Fischer-Tropsch Liquid Hydrocarbons. Journal of the Chinese Institute of Chemical Engineers, Volume 39(2), pp. 169-179 
Sotelo-Boyás, R., Liu, Y., Minowa, T., 2011. Renewable Diesel Production from the Hydrotreating of Rapeseed Oil with Pt/Zeolite and $\mathrm{NiMo} / \mathrm{Al}_{2} \mathrm{O}_{3}$ Catalysts. Industrial \& Engineering Chemistry Research, Volume 50(5), pp. 2791-2799

U.S. Department of Energy, 2007. Basic Research Needs: Catalysis for Energy. Basic Energy Sciences Workshop, Maryland, United States

Zhang, H., Lin, H., Wang, W., Zheng, Y., Hu, P., 2014. Hydroprocessing of Waste Cooking Oil over a Dispersed Nano Catalyst: Kinetics Study and Temperature Effect. Applied Catalysis B: Environmental, Volume 150-151, pp. 238-248 